\section{A needs based cognitive behavioural family intervention for schizophrenia reduced relapse in the long term}

Sellwood W,Barrowclough C, Tarrier N, et al. Needs-based cognitive-behavioural family intervention for carers of patients suffering from schizophrenia: 12-month follow-up. Acta Psychiatr Scand 2001 Nov;104:346-55.

\section{QUESTION: In outpatients with schizophrenia and their caregivers, does a needs based family intervention reduce relapse and caregivers' needs in the long term?}

\section{Design}

Randomised (unclear allocation concealment)*, blinded (outcome assessors)*, controlled trial with 12 months of follow up.

\section{Setting \\ South Manchester, UK.}

\section{Patients}

79 patient-caregiver dyads. Patients were $18-65$ years of age (mean age $36 \mathrm{y}, 65 \%$ men); met $I C D-10$ criteria for schizophrenia, schizoaffective disorder, or delusional disorder; had $\geqslant 1$ relapse of psychotic symptoms leading to inpatient admission in the previous 2 years; had $\geqslant 2$ years of illness (mean duration $13 \mathrm{y}$ ); and had $\geqslant 10$ hours of face to face contact with a caregiver each week over the previous month. Follow up was $80 \%$ for patients at 1 year and $88 \%$ for caregivers at 6 months.

\section{Intervention}

After stratification by sex, patient-caregiver pairs were allocated to standard care plus a family intervention $(\mathrm{n}=39)$ or standard care alone $(\mathrm{n}=40)$ for 24 weeks. Standard care consisted of psychiatric management by a clinical team, maintenance neuroleptic medication, monitoring through outpatient and community follow up, and the care programme approach to case management. The family intervention consisted of 10-20 treatment sessions of cognitive behavioural family interventions based on needs identified by caregivers through systematic assessment. 3 broad areas of intervention were given: problem solving techniques, cognitive behavioural intervention for families, and cognitive behavioural interventions for patients to reduce psychotic symptoms.

\section{Main outcome measures}

Relapse at 1 year and number of needs identified by caregivers (Relatives' Cardinal Needs Schedule).

\section{Main results}

Analysis was by intention to treat. Fewer patients in the intervention group than in the control group had relapses $(\mathrm{p}=0.003)$ or relapses that did not require hospital admission ( $\mathrm{p}=0.003$ ) (table). Hospital admission did not differ between groups (table). The groups did not differ for the number of caregivers' cardinal needs at 6 months; $\angle 80 \%$ of caregivers were assessed at 12 months.

\section{Conclusion}

A needs based cognitive behavioural family intervention for patients with schizophrenia and their caregivers was better than standard treatment for reducing relapse at 1 year. The groups did not differ at 6 months for number of needs identified by caregivers.

*See glossary.

\begin{tabular}{l} 
website extra \\
\hline Additional information \\
appears on the \\
Evidence-Based \\
Mental Health \\
website \\
www.ebmentalhealth. \\
com
\end{tabular}
com

\section{Source of funding: \\ National Health \\ Service Executive \\ Research and \\ Development Funds \\ from Tameside and \\ Glossop Community \\ and Priority Care \\ Trust. \\ For correspondence: $\operatorname{Dr} C$ Barrowclough, Tameside General \\ Hospital, Ashton under Lyne, UK. \\ christine.barrowclough \\ @man.ac.uk}

Family intervention plus standard care v standard care alone (control) for schizophrenia $\dagger$

\begin{tabular}{lllll} 
Outcomes at 1 year & Intervention & Control & RRR (95\% Cl) & NNT (CI) \\
Relapse & $37 \%$ & $72 \%$ & $49 \%(21$ to 68$)$ & 3 (2 to 8$)$ \\
\hline $\begin{array}{l}\text { Relapse not requiring } \\
\text { admission }\end{array}$ & $16 \%$ & $49 \%$ & $68 \%(31$ to 86$)$ & $4(2$ to 9$)$ \\
\hline Hospital admission & $29 \%$ & $38 \%$ & $25 \%(-40$ to 60$)$ & Not significant \\
\hline
\end{tabular}

†Abbreviations defined in glossary; RRR, NNT, and $\mathrm{Cl}$ calculated from data in article.

\title{
COMMENTARY
}

People with schizophrenia and other psychotic disorders have high rates of relapse and hospital readmission, which can lead to increased healthcare use and poor response to monotherapies. Although antipsychotic medications are frequently helpful in reducing psychotic symptoms and relapse, $>70 \%$ of clients are non-compliant with medication and up to $50 \%$ have persistent psychotic symptoms even when adhering to pharmacological treatment. ${ }^{1}$

Psychosocial interventions such as family psychoeducational treatment have proven effectiveness in reducing relapse in people with schizophrenia. Simi(1) cognitive behavioural treatment (CBT) is an emerging treatment that is effective in reducing psychotic symptoms and relapse. The study by Sellwood $e t$ $a l$ is the first to evaluate the effect of an innovative treatment model that combines family intervention with cognitive behavioural methods. Sellwood $e t$ al found an advantage for their combined family intervention over standard care that included medication and case management. Clients in this study appear representative of long term clients with schizophrenia (mean length of illness $13 \mathrm{y}$ ). An additional strength of this study is the high follow up rate at 1 year. The groups did not differ in the number of caregiver needs identified at 6 and 12 months. This may be because of the lower response rate of caregivers at 12 months. It also may be that it takes more than 12 months to reduce the needs of those who care for people with a severe and persistent illness. The family intervention provides a new model of treatment uniquely suited to patients who live with family or maintain family ties. It incorporates recent innovations in for people with schizophrenia with family interventions to meet the needs of family members.

The family intervention described in this study offers the potential to reduce the emotional and economic costs of relapse in schizophrenia. The promisthe efficacy and effectiveness of this intervention expands, this model could be adopted into existing mental health programmes. Dissemination of the treatWilliam Bradshaw, PhD University of Minnesota; Saint Paul, Minnesota, USA

1 Dickerson FB. Cognitive behavioral psychotherapy for schizophrenia: a review of recent empirical studies. Schizophr Res 2000;43:71-90. 